colour, especially when it depends on the staining techniques employed, is worth its high cost. The reproduction of all the illustrations is, no doubt, improved by the use of glazed paper throughout the book, but this also increases the weight of the volume. The bibliography is scarcely adequate for so comprehensive a book; it might have been better to have given to it the eight pages taken up by the list of equipment needed for a parasitological laboratory and the notes on the transport of diagnostic material. The book, nevertheless, strikes out a new line in the balance of its material, and anyone who has to deal with parasites encountered in European climates will find it a useful addition to his library.

G. LAPAGE

\section{EFFECTS OF SMOKING}

\section{Smoking}

Its Influence on the Individual and Its Role in Social Medicine. By C. Van Proosdy. Pp. viii +319 . (Amsterdam : Elsevier Publishing Company; London: D. Van Nostrand Company, Ltd., 1960.) $57 s$. $6 d$.

VER since its introduction into Europe at the end of the fifteenth century, tobacco-smoking has met with periodic opposition from temporal and ecclesiastical authorities, and other self-appointed guardians of public health and morals. Much of the criticism of the use of tobacco has been ill-founded and based on ignorance or prejudice, but in recent years a considerable body of scientific evidence has accumulated which indicates that tobacco-smoking may have deleterious effects on the smoker's health. The relationship between cigarette-smoking and lung cancer is now well established, and there is evidence that cigarette-smoking may also be connected with some forms of heart disease and certain other diseases. Most smokers would probably argue that smoking has beneficial effects as well, and it obviously has very strong attractions. These appear to be associated with the nicotine content of the smoke, and psychological and social factors may also be important.

In his book, Dr. Van Proosdy has brought together a great deal of the available evidence relating to the medical, psychological and social aspects of smoking. This is a very wide field with an extensive literature, and the herculean nature of Dr. Van Proosdy's labours is indicated by the bibliography, which occupies forty pages of the book. The pleasures of smoking are not entirely disregarded, but the emphasis is on its dangers and drawbacks, and nearly half the book is devoted to a discussion of "The Damage done by Tobacco to the Human Organism". This reviews the epidemiological and clinical evidence and also, where available, the experimental evidence, relating to the influence of smoking on the development of cancer of the lung, larynx and mouth, on other diseases of the respiratory tract, on diseases of the heart and blood vessels and on the digestive organs, nervous system and sexual organs. Other chapters are concerned with the psychological and pharmacological aspects of smoking and the use of tobacco as a socio-psychological phenomenon. Techniques used for investigating the effects of smoking and possible methods of making smoking less harmful are also discussed.

The coverage appears to be fairly complete, at least in the field with which I myself am most familiar, and moderately well up to date with references to results obtained up to and during the year 1959. The large amount of information given in a relatively small book makes for succinctness; the book is to be recommended as a useful work of reference on the medical, psychological and social aspects of smoking.

W. Carruthers

\section{FROM BUTTONS TO BULLION}

\section{Two Hundred Precious Metal Years}

A History of the Sheffield Smelting Company Limited, 1760-1960. By Ronald E. Wilson. Pp. xxii $+316+$ 54 illustrations. (London: Ernest Benn, Ltd., 1960.) 63s. net.

$\mathrm{N}$ these days of large corporations, it is rare to find a sizeable firm where a family has maintained a big interest for 200 years. The author of this book is a great-great-great-grandson of John Read, the founder of the Sheffield Smelting Co., which has been for a long time one of the most important preciousmetal smelting firms in the country. $H_{e}$ is thus in a unique position to survey the development of the firm which reflects, in some measure, the growth of Sheffield as a metallurgical centre. While this book will interest particularly those people familiar with the Sheffield scene, it provides the general reader with an accurate account of the early days of preciousmetal smelting in Hallamshire. At first, the prosperity of the infant firm rested in the skill with which gold and silver were recovered from jewellers' waste or sweep. As the Sheffield plate trade developed in the latter half of the eighteenth century Read's business flourished and already by 1783 he was selling more than 50,400 ounces of silver a year in Sheffield. In the early days the business contacts of the firm already ranged from the Royal Mint to the scores of button makers in Birmingham and Sheffield.

By the end of the century, the firm was smelting waste from many parts of the country and from Europe. There is ample evidence that dealings in precious metals were never without risk, for much depended on the skill of the assayer and the accuracy of the sample, not to mention the reliability of the Company's agents, which varied from time to time. Add to this the habit of gold and silver prices to change unpredictably, and the occasional imposition of precious-metal taxes, and one has all the necessary ingredients for an exciting commercial life. Consequently, in the nineteenth century, the fortunes of the Company waxed and waned, and disaster threatened from time to time. However, it is a measure of the resilience of the family that the firm survived to become the leading precious-metal smelters in Britain towards the end of the nineteenth century. The part of the book dealing with the eighteenth and nineteenth centuries is likely to be of greatest interest because of the many sidelights both on the social life and industrial development of the times.

While the twentieth century led to continued expansion and broadening of activities, the actions of Governments could turn fair wind into foul, as when the U.S. Treasury ceased to support the silver market in 1935. The author is perhaps more reticent about progress after the Second World War, but it is clear that since then there has been great development and that the Sheffield Smelting Co. commands a very important position among the refiners and fabricators of precious metals. 